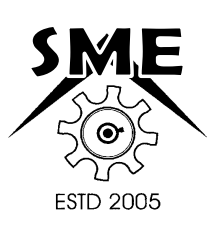

\title{
THE INFLUENCE OF MANUFACTURING PROCESSES AND OPTICAL MEASUREMENT METHODS ON THE DAMAGE BEHAVIOR OF HX340LAD MICRO-ALLOYED STEELS
}

\author{
*Mortaza Otroshi, Gerson Meschut and Aathavan Nesakumar
}

\author{
${ }^{1}$ Laboratory for Material and Joining Technology, Paderborn University, Paderborn, 33098, Germany
}

\begin{abstract}
This study deals with the damage behavior of metallic materials by the application of different manufacturing processes and using different optical measurement methods to identify the crack initiation in the damage specimen. The study is intended to highlight the importance of considering manufacturing processes and optical measurement methods in a numerical simulation when analyzing the damage behavior of metallic materials. To describe the damage behavior of the material in the process chain simulations, it is important to calibrate the parameters of damage model more accurately. These parameters are determined using experimental investigation of desired damage specimens. In this regard, a selected damage specimen manufactured by different cutting processes is first experimentally and then numerically investigated. It is shown that the manufacturing process and the optical measurement methods influence the stress state analyzed in the numerical simulation.
\end{abstract}

Keywords: Damage behaviour, Stress triaxiality, Manufacturing process and Optical measurement

\section{Introduction}

In order to continuously promote crash safety, failure prediction is constantly being investigated in the automotive industry. In order to consider the damage behavior of the material in the simulation, the damage and failure behavior of the material should be modelled using damage models. In general, the damage behavior of the material can be described by micro- and macro mechanical models. Micromechanical models describe the failure mechanisms from the microscopic point of view. In fact, the material is assumed to be inhomogeneous with existing defects and microcracks. From the category of micromechanical models Gurson [1], Tvergaard [2], Needleman [3], and the Rousselier [4] models could be mentioned. Macromechanical models are based on empirical observations and describe the damage behavior of the material using phenomenological approaches. Depending on the model, varieties of damage specimens should be experimental and numerical analyzed. The damage behavior is generally dependent on the stress state. This can be described by the triaxiality $\eta$ and the load angle parameter $\xi$, which can be derived from the principal stress components and the invariants of the stress tensor $[5]$.

The investigation of the influence of stress state on damage has already been investigated in some papers. In this respect, the work of Basaran investigated the influence of stress state on damage modeling, especially focusing on the lode angle parameter. By selection of different damage specimens from the material dual-phase steel DP600 such as notched round specimens among others notched flat tensile specimens, the desired stress states triaxiality as well as the lode angle parameter were generated [5]. In [6] the stress state dependent GISSMO damage model was used to describe the evolution of ductile damage and to predict the material failure during the simulation of self-piercing riveting process. To calibrate the model five damage specimens were manufactured using wire electrical discharge machining (EDM). The product and the material's capability can be influenced by the manufacturing process [7]. The influence of manufacturing process on hole production was investigated in [8] (Fig. 1). Two different manufacturing processes, reaming and punching (shearing) were used to produce the holes. It was shown that the production of the holes by shearing leads to lower failure strain compared to the reaming process. In [9], the influence of milling process on the hole expansion ratio of a punched sheet is investigated. It was reported that the milling process after the punching removes the accumulated shearing damage and leads to a higher expansion ratio. In [10] it was pointed out that the mechanical cutting process can initiate pre-damage at the cut edge and lead to a macroscopic crack. To avoid

*Corresponding Author - E- mail: motraza.otroshi@lwf.upb.de 
damage initiation, laser cutting was proposed as a suitable method. The Influence of cutting processes on the property of dual-phase and complex-phase steels was investigated in [11]. The influence of the manufacturing processes milling, drilling, and punching on the maximum reachable strain at the crack region was investigated for AHSS steel, DP800, and aluminum alloy AA5182 [12].

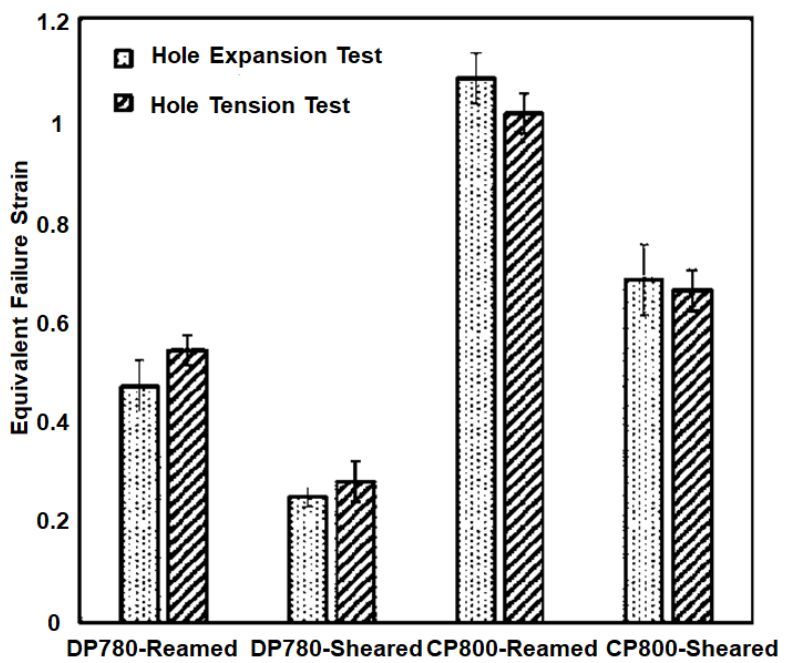

Fig. 1 Influence of manufacturing process on failure strain in hole expansion and tension tests [8]

In [13] the effects of manufacturing processes piercing and wire-cutting on stress state variables and subsequently on damage in terms of hole expansion ratio was investigated. It was pointed out that cutting processes can have an essential influence on the material's properties (Fig. 2).

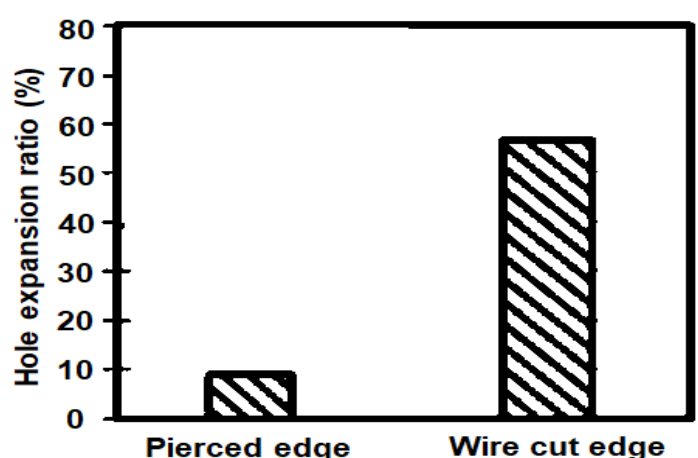

Fig. 2 Influence of manufacturing process on hole expansion ratio $[13]$
In none of the mentioned studies, the effect of machining process and damage measurement method on HX340LAD micro-alloyed steels has been investigated. The objective of the work is to improve the accuracy of damage modeling in the numerical simulations, in which the stress state dependent damage models are used. By accurate measuring of damage and damage relevant variables, the accuracy of crashworthiness simulations can be improved. Consequently, over dimensioning of components will be avoided and lightweight design will be achieved.

\section{Materials and Methods}

\subsection{Stress state variables}

To understand the subsequent numerical investigations, the stress state variables are introduced at this point. These are the triaxiality $\eta$ and the lode angle parameter $\xi$, which play a significant role in a damage analysis. The triaxiality $\eta$ influences the size of the voids and is formed from the ratio of the mean principal stress $\sigma_{m}$ and the equivalent stress $\sigma_{v m}$.

$$
\eta=\frac{\sigma_{m}}{\sigma_{v m}}
$$

The other stress state variable, the lode angle parameter $\xi$, which is responsible for changing the shape of the void is defined as follows:

$$
\xi=\frac{27}{2} \frac{J_{3}}{\sigma_{v m}^{3}}=\frac{3 \sqrt{3}}{2} \frac{J_{3}}{J_{2}^{3 / 2}}=\cos (3 \theta),
$$

where $J_{2}$ and $J_{3}$ are the second and the third invariants of the deviatoric stress tensor and $\theta$ is the lode angle.

\subsection{Material and specimen}

Notched flat tensile specimens with a radius of $4 \mathrm{~mm}$ manufactured from the micro-alloyed steel sheets (HX340LAD, thickness $=1.5 \mathrm{~mm})$ were used for the following study (Fig. 3). The specimens were manufactured by different cutting processes milling, wire-cut, and water jet. 


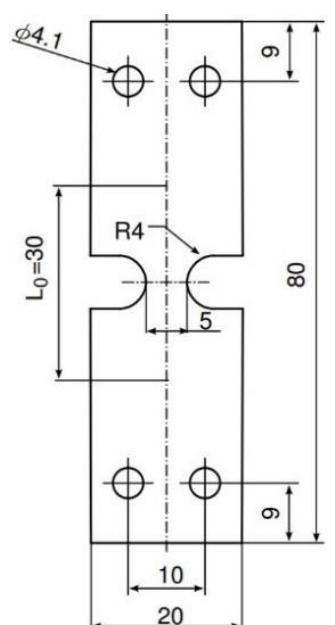

Fig. 3 The notched flat specimen radii $R=4 \mathbf{~ m m ~ [ 5 ] ~}$

The experiments were conducted on a Zwick Z100 tensile test machine under quasi-static loading condition. While the global force and displacement could be obtained directly from the machine, the local displacement was also needed for the local analysis. Therefore, the GOM Aramis optical measurement system and the high-speed camera were used to measure the displacement locally in the specimen. Prior to the test, it is necessarily to spray the specimens with a stochastic pattern, so that later the deformation can be properly measured by the GOM software. To generate the patterns, two different types of sprays were used: graphite and acrylic paints

The HX340LAD micro-alloyed steels are used in particular in the field of cold forming. Due to their good weldability and high strengths, they are used in highly stressed areas of bodywork and chassis. The chemical composition of the HX340LAD is summarized in the Table 1 [14].

Table 1 Chemical composition of the HX340LAD, according to DIN10268

\begin{tabular}{|c|c|c|c|c|c|c|c|c|}
\hline $\begin{array}{c}\text { HX340 } \\
\text { LAD }\end{array}$ & $\mathbf{C}$ & $\mathbf{S i}$ & $\begin{array}{c}\mathbf{M} \\
\mathbf{n}\end{array}$ & $\mathbf{P}$ & $\mathbf{S}$ & $\mathbf{T i}$ & $\begin{array}{l}\mathbf{N} \\
\mathbf{b}\end{array}$ & Al \\
\hline $\begin{array}{c}\text { Min. } \\
\text { Weight } \\
\%\end{array}$ & ' & ' & ' & ' & 1 & 1 & ' & $\begin{array}{l}n \\
0 \\
0\end{array}$ \\
\hline $\begin{array}{c}\text { Max. } \\
\text { Weight } \\
\%\end{array}$ & $\frac{1}{0}$ & $n$ & $?$ & ڤ̊. & 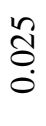 & $\frac{n}{0}$ & $\stackrel{8}{8}$ & ' \\
\hline
\end{tabular}

The niobium and titanium elements are responsible for the targeted strengths. Above the carbon content of $0.02 \%$, the niobium and titanium carbides in combination with a finely dispersed matrix produce high strength grades. These carbides have Vickers hardness of $2500-3000 \mathrm{HV}$. They represent significant barriers for the movement of dislocations during the forming process. The mechanical properties of the material such as elastic modulus, yield strength, tensile strength, and the Elongation at break were characterized using uniaxial tensile test. For the numerical simulation, in addition to the mechanical properties, the flow behavior of the material under quasi-static loading was identified. Five specimens were investigated, and the flow curves were extrapolated for large strain ranges using Ludwik approach. By measuring the fractured surface of the specimens and calculating the true stress and strain, the validity of the extrapolation approach was ensured (Fig. 4).

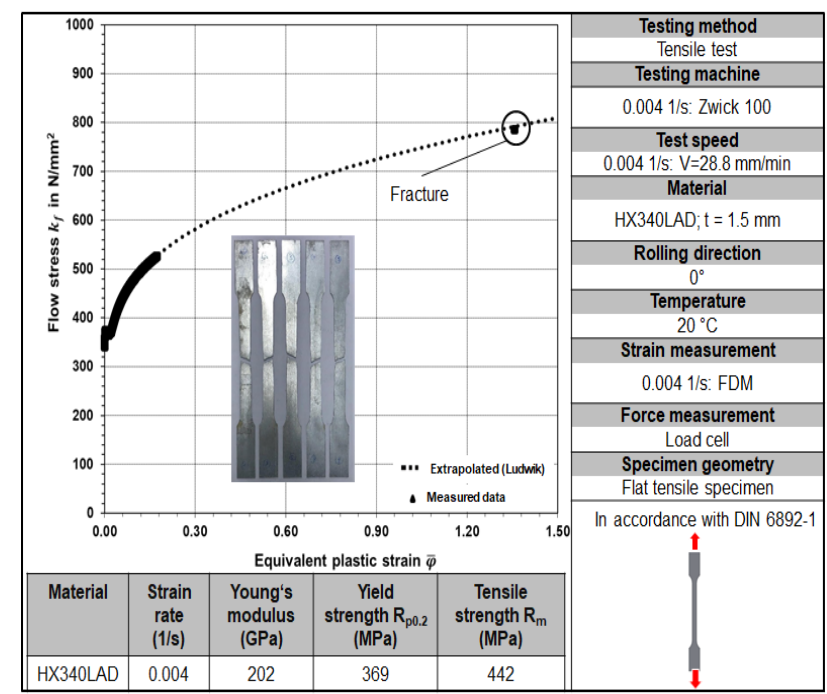

Fig. 4 Plasticity behavior and mechanical properties of HX340LAD

\subsection{Numerical FEM simulation}

The numerical FEM simulation software LSDYNA was used to investigate the stress state as well as the failure strain of the specimen. Due to symmetry conditions, only $1 / 8$ of the notched flat specimen was considered for the numerical simulation. This allows a considerable reduction of computation time. The specimen was meshed using solid elements with an element size of $0.05 \mathrm{~mm}$ in the region of the notch and a coarser mesh up to $0.25 \mathrm{~mm}$ away from the notch. 


\section{Results and Discussions}

3.1 Influence of manufacturing processes in terms of force-displacement curves

The force-displacement curves of the experiments for the specimens manufactured by wire cut, milling, and water jet cutting processes are compared in Fig. 5. It can be seen that experiments are reproducible and the manufacturing process has an influence on the results in terms of force-displacement diagram. It can be explained through different mechanical and thermal loads applied by each process as well as different geometrical tolerances. Considering the water jet process, high compressive stresses are applied which could cause an increase in strength of the material. In addition, after manufacturing the specimens, it was noticed that the specimens manufactured by water jet have a greater surface area than the ones manufactured by wire cut and milling cutting processes.

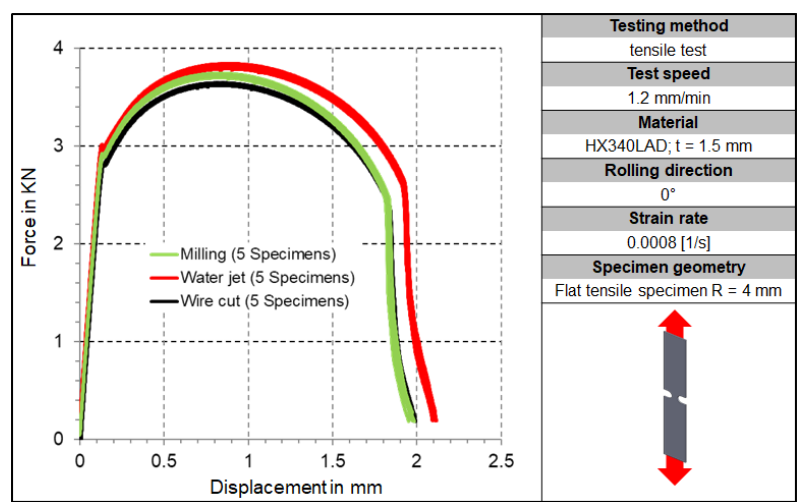

Fig. 5 Comparing the manufacturing processes in terms of force-displacement curves

\subsection{Influence of manufacturing processes on the} failure location

The location of the crack initiation was identified using the GOM optical measuring system. To focus only on the influence of manufacturing processes, the same spray as well as the same camera were used for the investigation. Comparison of the crack initiation locations in Fig. 6 shows that the crack initiation occurs in the center of the specimen regardless of the manufacturing process. It can be concluded that the manufacturing process has no influence on the crack initiation location.

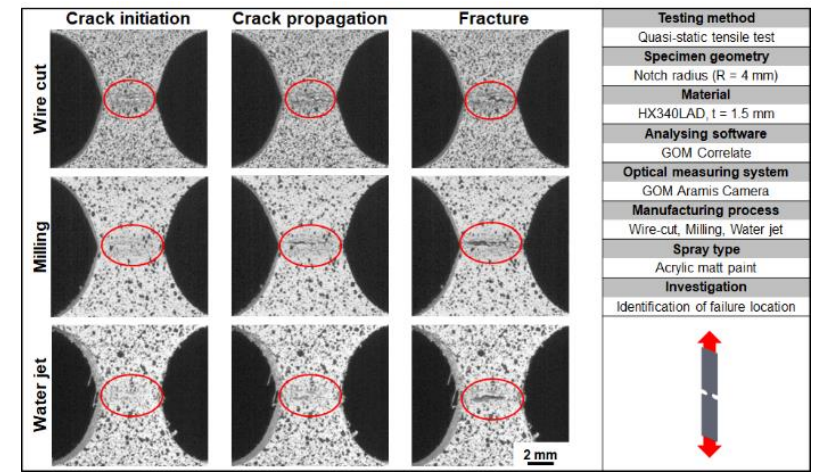

Fig. 6 Influence of manufacturing processes on the failure location

\subsection{Influence of manufacturing processes on the stress state}

The evaluation of the stress triaxiality and the plastic strain in the simulation was performed at the failure location. Since the center of the specimen was identified to be the failure location for all three manufacturing processes, the elements located there were selected for the analysis. Although the location of crack initiation is the same for all three manufacturing processes, the processes differ in terms of displacement at failure. The difference between the wire cut and milling is small. However, the crack on the specimen produced by the water jet cutting process occurs at a later stage, which can also be expected from the Fig. 5. The resulting triaxiality values of the differently manufactured specimens show that there is a biaxial tension stress state in the failure location at the time of failure. Furthermore, the plastic strain at failure was analyzed in the simulation. In Fig. 7, it can be seen that there are differences with regard to the plastic strain. It can be concluded that the manufacturing processes has a certain influence on the deformation behavior of the material. This could be due to material-physical effects, such as mechanical and thermal stresses as well as different geometrical tolerances, which are introduced into the speciemen by the manufacturing process. 


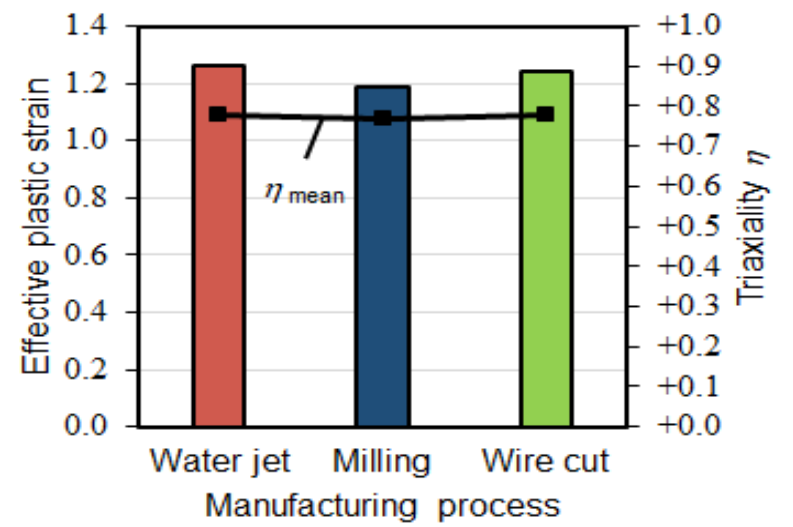

Fig. 7 Influence of manufacturing processes on fracture strain and triaxiality

\subsection{Identification of the crack initiation using different sprays}

Two types of sprays were used to analyze the influence of the quality of the spray on the detection of crack initiation. In this regard, the specimens were sprayed using Acrylic and Graphite sprays. For the investigation, the same manufacturing process and the same optical measurement system were used. The results of optical images are shown in Fig. 8. It can be seen that the crack initiation in the specimen sprayed with acrylic is visually more clear and recognizable than the one sprayed by graphite. In other words, using the graphite spray leads to a later detection of crack initiation due to poor quality of the spray.

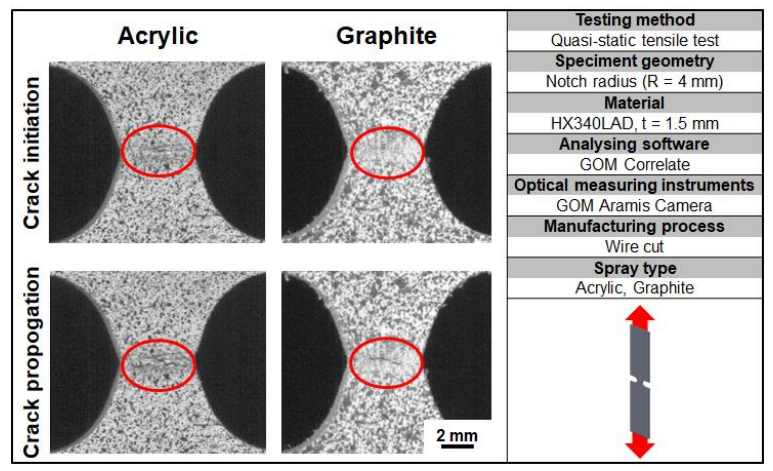

Fig. 8 Influence of the type of spraying on the identification of crack initiation
3.5 Identification of the crack initiation using different measuring systems

To analyze the influence of optical measurement systems on crack detection, the images were captured using the high speed camera. It can be observed that the quality of the images taken by GOM Aramis optical measurement system is better than the one taken by high speed camera. Accordingly, only a rough visualization is possible by using the high speed camera, and it is difficult to precisely recognize the crack initiation location and time (see Fig. 9).

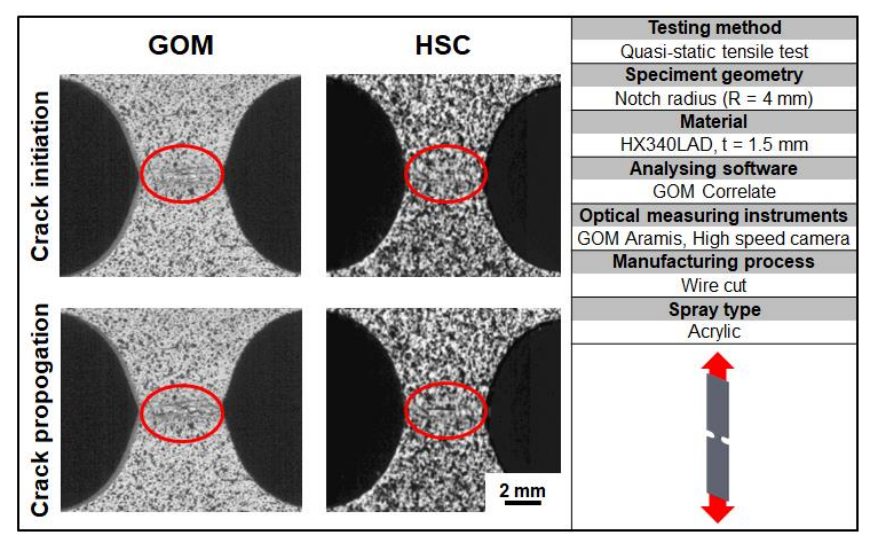

Fig. 9 Influence of the optical measurement system on the identification of crack initiation

The influence of using different evaluation methods was analyzed in the numerical simulation. The elements were selected at the failure location and times determined from the experiments. Based on the results shown in Fig. 10 and Fig. 11, it can be concluded that despite different failure times, the elements are in the same stress state. However, a deviation with respect to the plastic strain at failure can be seen. Since the evaluation methods used specimens of the same manufacturing process, the differences in plastic strains are caused by different spaying and measuring systems. 


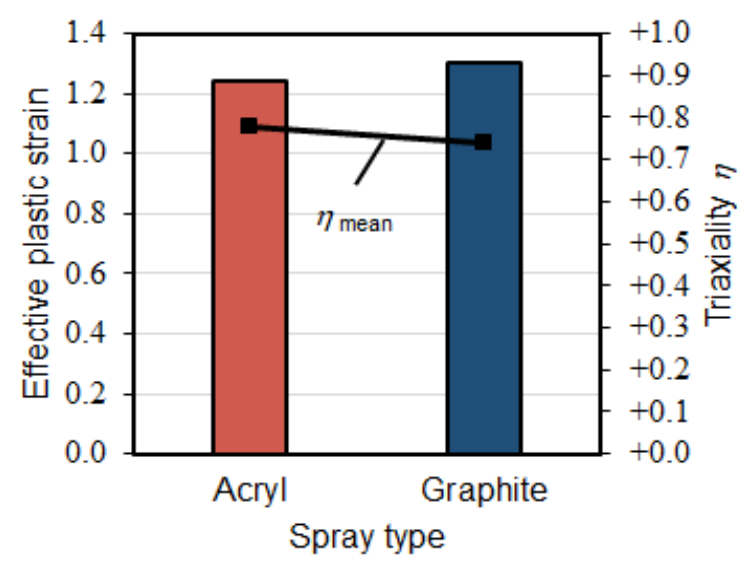

Fig. 10 Influence of type of spraying on the identification of fracture strain and stress triaxiality

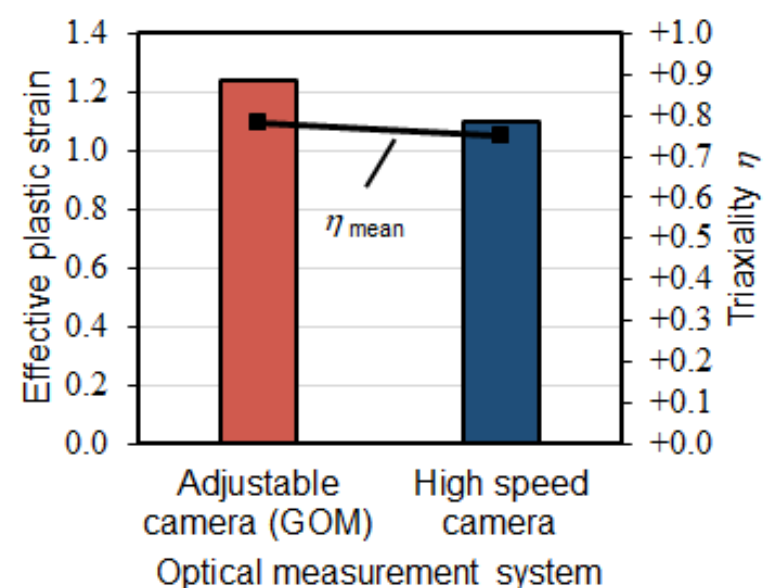

Fig. 11 Influence of optical measurement system on the identification of fracture strain and stress triaxiality

\section{Conclusions}

In this paper, the effects of manufacturing processes milling, wire cut, and water jet on the damage behavior of the notched flat tensile specimen HX340 $\mathrm{LAD}(\mathrm{t}=1.5 \mathrm{~mm})$ was investigated. It was shown that the manufacturing process has an influence on the forcedisplacement diagram. Besides, the results of optical measurement and numerical simulation show that the location of crack initiation and the stress state is the same for the different manufacturing processes. However, the plastic strain at failures is different. Furthermore, the influence of different sprays used for specimen preparation and the optical measurement systems on the crack detection was investigated. It was shown that the type of spray and the optical measurement system influence the accuracy of crack detection and the following analysis. In fact, poor quality of images due to type of spray or optical measurement system leads to a later detection of crack initiation. By comparing the results of numerical simulation, it was seen that different evaluation methods lead to the different simulation results in terms of plastic strain at failure. This is important for the subsequent damage modelings. Especially for the stress-state dependent damage models, the accuracy of the determined fracture strain and stress state is important for the calibration of the damage model. In this work, a simple geometry of the damage specimen was used. For future analyses, more complicated geometries could also be investigated. By considering the influence of manufacturing processes and measurement methods for other damage specimens (stress states), the prediction accuracy of process simulations (For example self-piercing riveting), in which the damage model is used, will be improved.

\section{Acknowledgments}

The presented results are taken from the IGF research project $19452 \mathrm{~N}$ of the European Research Association for Sheet Metal Working (EFB), which has been funded by the German Federation of Industrial Research Associations (AiF) under its program for the promotion of industrial research (IGF) by the Federal Ministry for Economic Affairs and Energy (BMWi) based on a decision of the German Bundestag.

\section{References}

1. Gurson A.L., (1977), Continuum theory of ductile rupture by void nucleation and growth, 1. Yield criteria and flow rules for porous ductile media. J. Eng. Mater T. Asme, 2. 99(1):2-15.

2. Tvergaard V., (1981), Influence of voids on shear band instabilities under plane strain conditions. Int. J. Fract., 17:389407.

3. Needleman A., (1987), A continuum model for void nucleation by inclusion debonding. J. Appl. Mech., 54(3):525-531.

4. Rousselier G., (1987), Ductile fracture models and their potential in local approach of fracture Nuc. Eng. Design 105, S. 97-111.

5. Basaran M., (2011), Stress State Dependent Damage Modeling with a Focus on the Lode Angle Influence. Aachen: Shaker Verlag.

6. Otroshi M., Rossel M., and Meschut G., (2020), Stress state dependent damage modelling of self-pierce riveting process simulation using GISSMO damage model. In: Journal of Advanced Joining Processes https://doi.org/10.1016/j.jajp.2020.100015

7. Tekkaya A.E., Bouchard P.-O., Bruschi S., Tasan C.C., (2020), Damage in metal forming CIRP Ann. - Manuf. Technol., 35 (2020), pp. 1-24. 
8. Pathak N., Butcher C., Worswick M., Bellhouse E., and Gao J., (2017), Damage Evolution In Complex-Phase And Dual-Phase Steels During Edge Stretching. Materials 10/4:346.

9. Yoon JI., Jung J., Lee HH., Kim G-S., and Kim HS., (2016) Factors Governing Hole Expansion Ratio Of Steel Sheets With Smooth Sheared Edge. Metals and Materials International 22/6:1009-1014.

10. Mohrbacher H., (2013), Reverse Metallurgical Engineering Towards Sustainable Manufacturing Of Vehicles Using NB And MO Alloyed High Performance Steels. Advances in Manufacturing 1/1:28-41.

11. Karelova A. and Krempuszky C., (2007), Influence of the Edge Condition on the Hole Expansion Property of Dual Phase and Complex Phase", MS\&T, pp.159-169.

12. Tsoupis I and Merklein M. (2016), Edge crack sensitivity of lightweight materials under different load conditions, IOP Conf. Ser.: Mater. Sci. Eng. 159012017.

13. Habibi N., Beier T., Richter H., Konemann M., and Münstermann S., (2019), The Effects Of Shear Affected Zone On Edge Crack Sensitivity In Dual Phase Steels. In: Proceedings of the 38th International Deep Drawing Research Group Annual Conference.
14. Friedrich, H-E.., (2013), Leichtbau in der Fahrzeugtechnik. Springer Fachmedien Wiesbaden.

\section{Nomenclature}

\begin{tabular}{c|l|l}
\hline Symbol & Meaning & Unit \\
\hline$\eta$ & Triaxiality & - \\
$\sigma_{m}$ & Mean normal stress & $\mathrm{N} / \mathrm{mm}^{2}$ \\
$\sigma_{v m}$ & Equivalent stress & $\mathrm{N} / \mathrm{mm}^{2}$ \\
$J_{2}$ & Second invariant of deviatoric & $\mathrm{N} / \mathrm{mm}^{2}$ \\
$J_{3}$ & stress tensor & \\
$\xi$ & Third invariant of deviatoric & $\mathrm{N} / \mathrm{mm}^{2}$ \\
$\theta$ & Lodess tensor & \\
\hline
\end{tabular}

